\title{
Balloon-Assisted Enteroscopy and Capsule Endoscopy in Suspected Small Bowel Crohn's Disease
}

\author{
Hsu-Heng Yen ${ }^{1,2}$, Chen-Wang Chang ${ }^{3,4,5}$, Jen-Wei Chou ${ }^{6}$ and Shu-Chen Wei ${ }^{7}$ \\ ${ }^{1}$ Department of Gastroenterology, Changhua Christian Hospital, Changhua, ${ }^{2}$ General Education Center, Chienkuo Technology University \\ Changhua, ${ }^{3}$ Division of Gastroenterology, Department of Internal Medicine, MacKay Memorial Hospital, Taipei, ${ }^{4}$ MacKay Junior College \\ of Medicine, Nursing and Management, Taipei, ${ }^{5}$ MacKay Medical College, New Taipei City, ${ }^{6}$ Division of Gastroenterology and Hepatology, \\ Department of Internal Medicine, China Medical University Hospital, Taichung, 'Department of Internal Medicine, National Taiwan University \\ Hospital and College of Medicine, Taipei, Taiwan
}

Inflammatory bowel diseases are idiopathic inflammatory diseases of two main types, Crohn's disease and ulcerative colitis. Crohn's disease can affect the entire gastrointestinal tract, and the distal ileum is involved in up to $70 \%$ of patients. Moreover, Crohn's disease in one-quarter to one-third of patients involves isolation of the small bowel. Due to the nonspecific symptoms and anatomical location of the disease, small bowel Crohn's disease is a phenotype that is particularly difficult to manage. Since the introduction of capsule endoscopy in 2000 and balloon-assisted enteroscopy in the 21st century, it is now possible to directly inspect for small bowel Crohn's disease. However, the new modalities still have limitations, such as capsule retention and invasiveness of balloon-assisted enteroscopy. The diagnostic yields of both capsule endoscopy and balloon-assisted enteroscopy are high for patients with suspected small bowel Crohn's disease. Therefore, earlier use of capsule endoscopy or balloon-assisted enteroscopy can help with the diagnosis and earlier treatment of these patients to avert possible disastrous outcomes. Clin Endosc 2017;50:417-423

Key Words: Small bowel Crohn's disease; Balloon-assisted enteroscopy; Capsule endoscopy

\section{INTRODUCTION}

Inflammatory bowel diseases (IBDs) are idiopathic inflammatory diseases affecting the gastrointestinal tract. IBDs can be categorized broadly into two types, Crohn's disease (CD) and ulcerative colitis (UC). ${ }^{1} \mathrm{CD}$ can involve the entire gastrointestinal tract and cause intestinal mucosal and transmural inflammation. CD with gastrointestinal tract ulceration and prolonged ulceration with transmural inflammation and fibrosis can lead to lumen stricture and fistula. ${ }^{1-3}$

Diagnosis and management of terminal ileal CD can usually be performed with ileo-colonoscopy; however, small bowel

Received: September 4, 2017 Accepted: September 17, 2017

Correspondence: Shu-Chen Wei

Department of Internal Medicine, National Taiwan University Hospital and College of Medicine, No.7 Chung-Shan South Road, Taipei 101, Taiwan

Tel: +886-2-23123156, Fax: +886-2-23940049, E-mail: shuchenwei@ntu.edu.tw

(cc) This is an Open Access article distributed under the terms of the Creative Commons Attribution Non-Commercial License (http://creativecommons.org/ licenses/by-nc/3.0) which permits unrestricted non-commercial use, distribution, and reproduction in any medium, provided the original work is properly cited.
$\mathrm{CD}$ requires other new diagnosis techniques. Over the past decade, the published research has suggested that small bowel capsule endoscopy (CE) and balloon-assisted enteroscopy (BAE) are efficacious in the treatment of small bowel CD. ${ }^{1}$ In this review, we discuss the efficacy and limitations of CE and BAE for treatment of suspected small bowel CD.

\section{SMALL BOWEL CROHN'S DISEASE}

$\mathrm{CD}$ is a heterogeneous disease comprising several different phenotypes that can affect the entire gastrointestinal tract. ${ }^{4}$ According to the 2005 Montreal classification of CD, patients are classified according to their "age at diagnosis", "disease location", and "disease behavior". Small bowel CD can occur in up to $70 \%$ of patients with $\mathrm{CD}$, and the distal ileum is the most commonly affected site. Moreover, isolated small bowel disease can occur in up to one-third of patients with $\mathrm{CD}^{1,5}$

Isolated small bowel CD is a particularly difficult phenotype to identify and manage due to its nonspecific symptoms 
and anatomical location. ${ }^{1}$ Up to $13 \%$ of normal asymptomatic people are diagnosed with small bowel lesions through $\mathrm{CE} .{ }^{4}$ Small bowel CD is highly resistant to current treatments; therefore, it leads to complications over time, such as strictures and performation in terms of complications such as stricture and perforation. ${ }^{1}$ Its clinical response does not correlate with mucosal healing. ${ }^{6}$ Therefore, direct observation of the small bowel mucosa is necessary to ensure that mucosal healing or deep remission is achieved for these patients.

In the past, small bowel CD could only be assessed by small bowel follow through (SBFT); more recently, cross-sectional images such as computed tomography enterography (CTE) or magnetic resonance enterography (MRE) have become useful. With the introduction of $\mathrm{CE}$ and $\mathrm{BAE}$, we can now directly inspect the entire small bowel.

\section{CAPSULE ENDOSCOPY}

\section{Role, efficacy, and limitations of CE in cases of sus- pected CD}

Since its introduction in 2000, CE has served as a noninvasive tool for the direct visualization of the entire small intestinal mucosa, which was previously inaccessible by conventional endoscopic techniques. ${ }^{7}$ As technology has evolved, five different $\mathrm{CE}$ systems have become available: Medtronic Pillcam SB3, Intromedic MiroCam, Olympus EndoCapsule, Jinshan Science and Technology OMOM capsule, and CapsoVision CapsoCam SV3. Each differs slightly in design (i.e., capsule size, number of cameras, weight, image frame rate, image transmission method, and image capture battery life), but they do not differ substantially in diagnostic yield. ${ }^{8}$

$\mathrm{CD}$ is a chronic inflammatory disorder the potentially involves the entire gastrointestinal tract. ${ }^{9}$ Ileo-colonoscopy is a commonly used tool to diagnose and assess disease activity among patients with $\mathrm{CD}$ to guide treatment and improve patient outcomes with mucosal healing. However, the small bowel is involved in one-quarter to one-third of patients, and a diagnostic delay is not uncommon using conventional diagnostic tests. Fireman et al. first reported a high diagnostic yield $(71 \%)$ of $\mathrm{CE}$ to diagnose patients with small bowel $\mathrm{CD} .^{10}$ Girelli et al. reported the use of CE for suspected small bowel CD with a diagnostic yield of 59\%, sensitivity of $93 \%$, and specificity of $84 \%$ during long-term follow-up. ${ }^{11}$

Some common findings from using $\mathrm{CE}$ in patients with $\mathrm{CD}$ include erythema, mucosal edema, ulceration, loss of villi, mucosal fissures, and stenosis (Fig. 1). ${ }^{12}$ For CD activity monitoring, two CE scoring systems, the Lewis score and the CE CD Activity Index, can be used to provide endoscopic assessment of disease activity during $\mathrm{CE} \cdot{ }^{13,14} \mathrm{CE}$ findings of mucosal lesions alone are insufficient to establish a diagnosis of CD, especially in the absence of typical symptoms, lack of increased inflammatory markers, or supportive findings through small bowel imaging. ${ }^{15}$ A differential diagnosis of small bowel ulcers found during $\mathrm{CE}$ includes medication (i.e., enteropathy induced by nonsteroidal anti-inflammatory drugs [NSAIDs], radiation enteritis, intestinal tuberculosis, and Behcet's disease). ${ }^{16}$ It is generally recommended that NSAIDs be stopped 4 weeks prior to $\mathrm{CE}$ examination for suspected $\mathrm{CD}^{8,13}$

The clinical presentation of $\mathrm{CD}$ commonly features abdominal pain, weight loss, and prolonged diarrhea, especially in young patients. ${ }^{9,15,17}$ A clinical history of diarrhea or abdominal
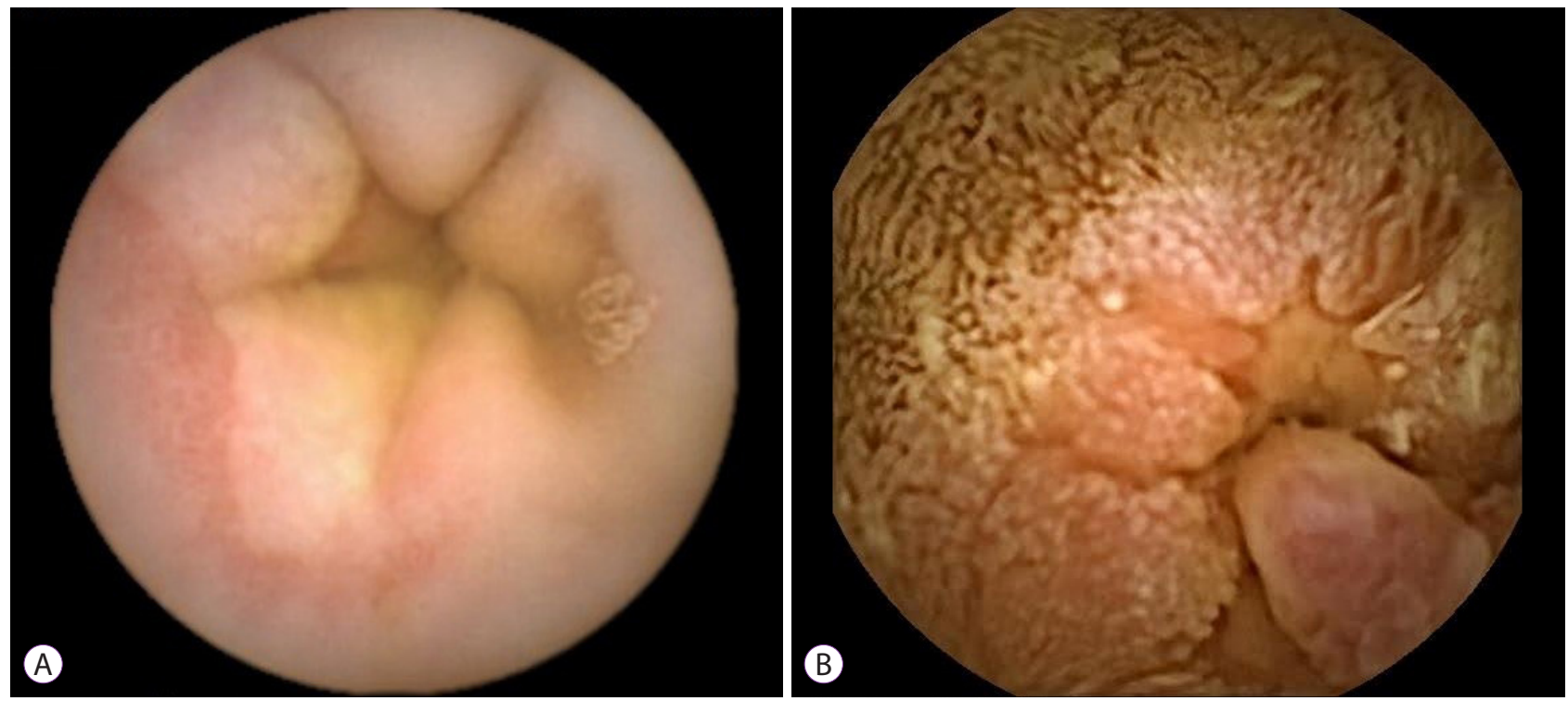

Fig. 1. Small bowel Crohn's disease images captured by capsule endoscopy. (A) Deep ulceration of the jejunum. (B) Ulcerative stenosis of the ileum. 
pain for $>6$ weeks with laboratory findings of inflammation, such as elevated C-reactive protein, elevated erythrocyte sedimentation rate, or increased fecal calprotectin level, is suggestive of $\mathrm{CD} .{ }^{15} \mathrm{~A}$ meta-analysis reported a low diagnostic rate of $\mathrm{CE}$ when the fecal calprotectin level was $<50 \mu \mathrm{g} / \mathrm{g}^{18}$ therefore, $\mathrm{CE}$ is not warranted for investigation in patients with chronic pain or diarrhea as the sole symptom without evidence of inflammation or radiological abnormalities. ${ }^{12,15,17} \mathrm{CE}$ is more sensitive than other imaging modalities for detecting mucosal changes in the small bowel. In addition to ileo-colonoscopy, CE provides information about the small bowel mucosa and disease extent. ${ }^{19}$ When $\mathrm{CD}$ involves the small bowel distal to the duodenum and proximal to the terminal ileum, ileo-colonoscopy may result in a negative finding. Overall, $\mathrm{CE}$ is a recommended tool for patients with clinical features suggestive of $\mathrm{CD}$ but with negative ileo-colonoscopy findings. ${ }^{8,15,16,20} \mathrm{CE}$ is also helpful for reclassifying patients with colonic IBD who are not classified as having $\mathrm{CD}$ or UC.

The reported diagnostic yield of $\mathrm{CE}$ for suspected $\mathrm{CD}$ was
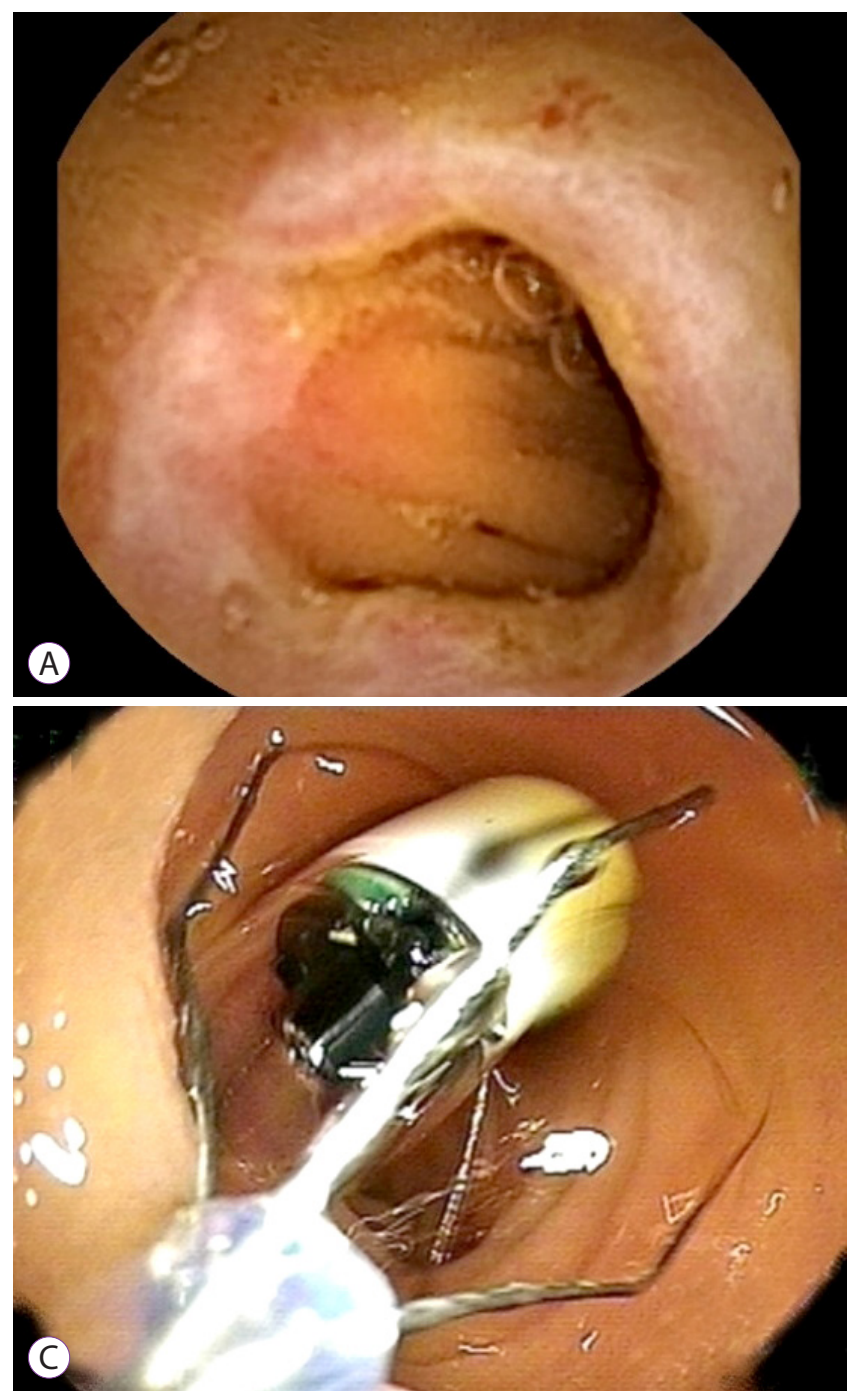

$52 \%-68 \%$ in a meta-analysis of 12 trials. ${ }^{21}$ The use of CE for suspected CD has an overall diagnostic accuracy of $83.2 \%$ sensitivity of $89.5 \%$, specificity of $78.9 \%$, positive predictive value of $73.9 \%$, and negative predictive value of $91.8 \%$ using a Lewis score cutoff value of $\geq 135 .{ }^{14}$ In contrast, a negative CE for suspected $\mathrm{CD}$ has a very high negative predictive value of $96 \%$ for ruling out CD during follow-up. ${ }^{22,23}$ In the absence of significant small bowel inflammatory activity, $\mathrm{CE}$ helps clinicians exclude the diagnosis of $\mathrm{CD}$ in $94 \%$ of cases. ${ }^{24}$

Compared with other imaging modalities, $\mathrm{CE}$ has the advantages of being noninvasive, enabling a direct mucosal examination, and excellent visualization of the proximal small bowel, but it is limited by its inability to obtain biopsy specimens and the potential risk of capsule retention in stricturing $\mathrm{CD}{ }^{8}$

\section{Comparison of $\mathrm{CE}$ with radiological study in cases of suspected CD}

Compared with a radiologic study, CE can depict small

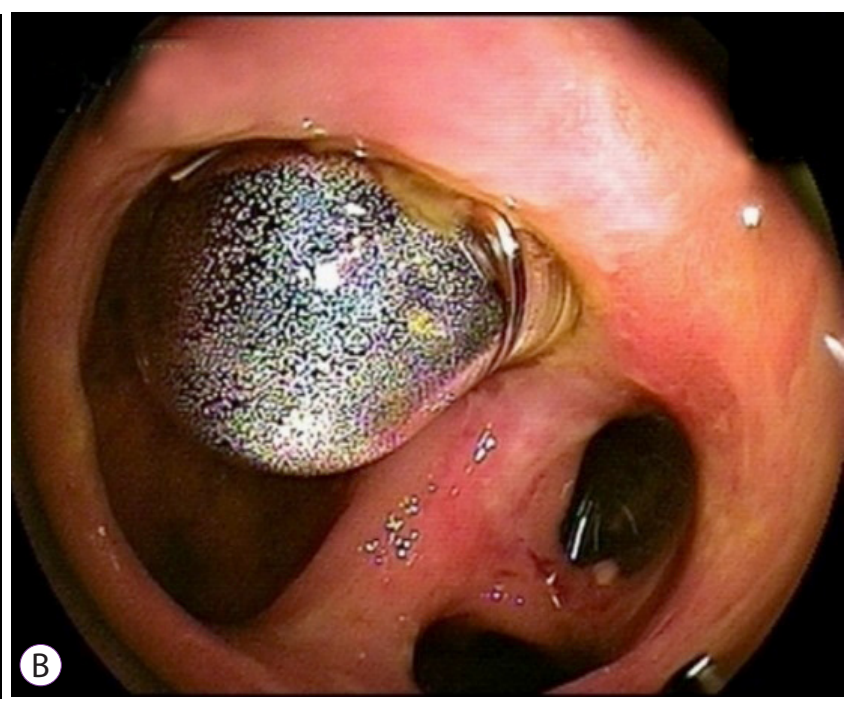

Fig. 2. Retention of capsule endoscope and endoscopic retrieval. (A) Capsule endoscopy finding of stenosis of the jejunum. (B) Capsule retention for 2 weeks, revealed by oral-route enteroscopy. (C) Successful retrieval of the retained capsule via enteroscopy. 
bowel ulcers, villous changes, and proximal disease, whereas a radiologic study is better for demonstrating extraluminal disease (i.e., abscesses or fistula and excluding patients with strictures). Several reports have compared CE with radiologic studies in cases of suspected small bowel CD. In one meta-analysis of 19 studies of patients with suspected $\mathrm{CD}, \mathrm{CE}$ was compared with SBFT, enteroclysis (EC), CTE, and MRE. ${ }^{20}$ The diagnostic yield of $\mathrm{CE}$ was significantly higher than that of SBFT ( $66.0 \%$ vs $21.3 \%$, respectively, $p<0.00001)$ and EC (75.7\% vs $29.4 \%$, respectively, $p<0.0008){ }^{20}{ }^{20}$ However, CE did not display a superior diagnostic yield compared to CTE ( $72.5 \%$ vs $22.5 \%$, respectively, $p=0.19$ ) or MRE ( $85.7 \%$ vs $100 \%$,

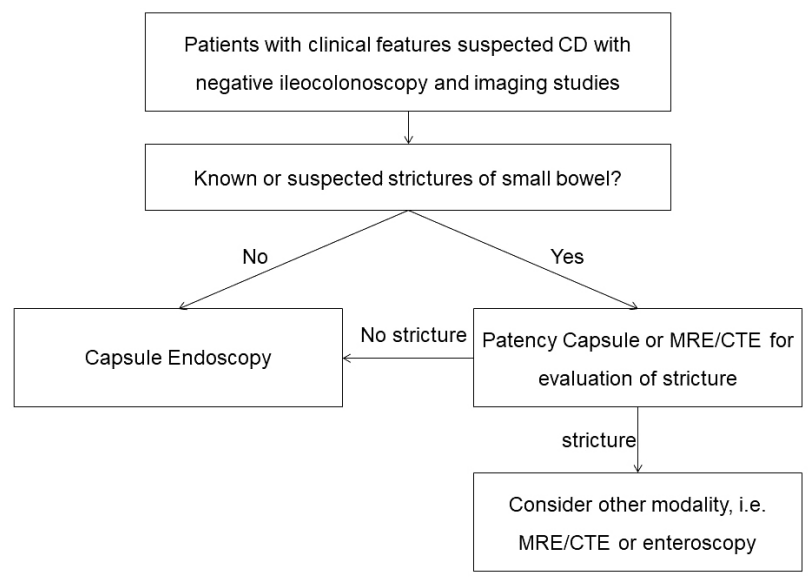

Fig. 3. Role of capsule endoscopy in suspected Crohn's disease proposed by Van de Bruaene et al. ${ }^{31} \mathrm{CD}$, Crohn's disease; MRE, magnetic resonance enterography; CTE, computed tomography enterography. respectively, $p=0.52){ }^{20}$ Regarding patients with suspected $C D$, two studies reported that the sensitivity and specificity of CE were $62 \%-100 \%$ and $50 \%-100 \%$, respectively, whereas those for MRE were $77 \%$ and $80 \%$, respectively. ${ }^{20}$ In one prospective blind study, CE reportedly had a similar overall diagnostic yield to that of MRE or CTE. ${ }^{25}$ The authors found that MRE and CTE missed lesions that were primarily superficial and proximal to the terminal ileum compared with $\mathrm{CE}(p<0.05)$ and recommended $\mathrm{CE}$ as the first-line modality for the detection of small bowel $\mathrm{CD}$ beyond the reach of colonoscopy.

\section{Risk of capsule retention}

As a noninvasive study, the main concern of $\mathrm{CE}$ is capsule retention, which is defined as failure to pass for $>2$ weeks; the longest reported capsule retention was 6 years and 10 months. ${ }^{26,27}$ Risk factors for capsule retention include known small strictures, a history of small bowel obstruction, previous bowel surgery, and extensive small bowel $\mathrm{CD}^{28}$ Although most cases of capsule retention are asymptomatic, its management includes surgical removal, extraction by deep enteroscopy (Fig. 2), or the administration of a short course of anti-inflammatory therapy. ${ }^{8,26}$ A meta-analysis found a retention rate of 3.6\% for suspected IBD and 8.2\% for established IBD compared with $2.2 \%$ for other indications. ${ }^{29}$ The rate of $\mathrm{CE}$ retention decreased by half in the post-performance analysis of a patency capsule or CTE in patients with IBD to exclude strictures. ${ }^{29}$ Small bowel radiological evaluations or the use of patency capsule examinations is recommended before $\mathrm{CE}$ in the evaluation of patients with suspected or es-

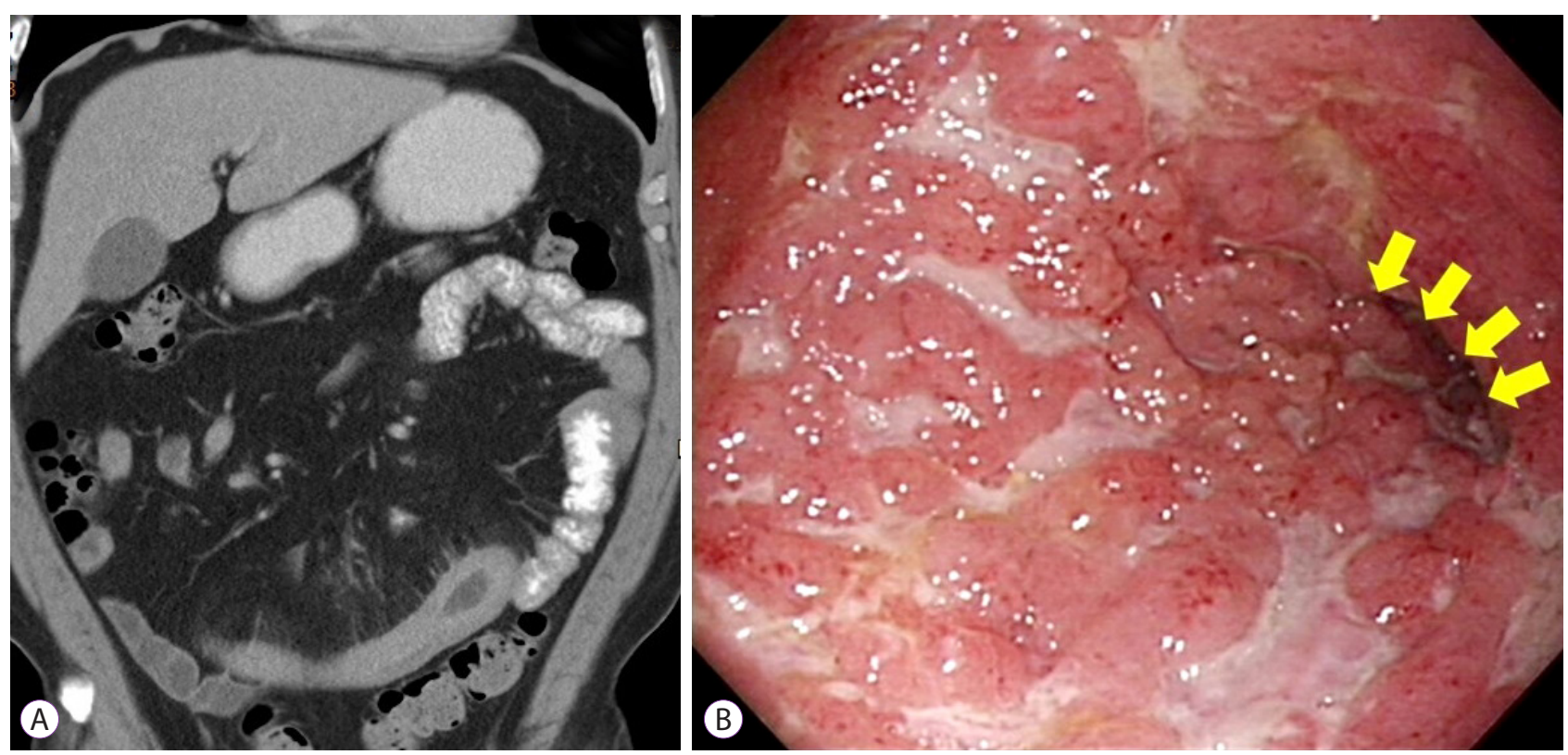

Fig. 4. A 37-year-old man reported chronic abdominal pain for more than 2 years. Abdominal computed tomography revealed (A) swelling of the small bowel wall. (B) Small bowel Crohn's disease with ulceration and stricture (yellow arrow) was diagnosed via single-balloon enteroscopy. 
tablished $\mathrm{CD}^{29,30}$ A proposed use of $\mathrm{CE}$ for suspected CD is illustrated in Fig. 3. ${ }^{31}$

\section{BALLOON-ASSISTED ENTEROSCOPY}

BAE, including single-balloon enteroscopy (SBE) and double-balloon enteroscopy (DBE), is an examination of the small bowel using any endoscopic technique that includes a balloon-assisted procedure. The development of BAE has revolutionized small bowel examinations and has major implications for the histological diagnosis and therapy of small bowel CD (Fig. 4). ${ }^{4}$ BAE may also be the first-line tool for patients with capsule retention due to the possibility of small bowel strictures. $^{32}$

\section{DBE in cases of suspected small bowel CD}

DBE, developed in 2001 by Yamamoto et al., is a useful tool in the diagnosis and therapy of small bowel CD. ${ }^{33,34} \mathrm{DBE}$ can clarify diagnoses in patients with suspected small bowel CD with a $30 \%-80 \%$ diagnostic yield. ${ }^{4,35,36}$ In one study of 399 cases of DBE, 122 procedures were performed in 100 patients with suspected CD. The DBE findings were positive in $60 \%$ of patients, an alternative diagnosis was made in $12 \%$, and $45 \%$ of the patients received treatment for $\mathrm{CD}^{37}$ In another retrospective study of $98 \mathrm{DBE}$ procedures performed in 43 patients with suspected CD, the diagnostic yield was $79 \%$ (34/43 patients). ${ }^{35}$ A study of multiple medical centers in Korea also indicated that DBE is a promising alternative and useful technique for patients with suspected $C D$, with a diagnostic rate of $\mathrm{CD}$ in $80 \%$ of patients $(24 / 30) .{ }^{36}$ A large prospective DBE database in Germany with a total of 2,245 prospectively reported DBE procedures performed in 1,765 patients indicated pathological findings in 91 of 193 patients with known or suspected CD (47\%). ${ }^{38}$

\section{SBE in small bowel CD}

SBE, introduced in 2007, uses an enteroscope with an overtube and only one silicone balloon. SBE uses a simpler device than DBE and is more convenient to use. ${ }^{33,39,40}$ In one study of $73 \mathrm{SBE}$ procedures performed in 70 patients, including nine with suspected small bowel $\mathrm{CD}$, small bowel CD was diagnosed in four patients. ${ }^{41}$

SBE is also a safe and useful endoscopic procedure for pediatric patients with suspected small bowel CD; in one study, among 16 such patients, SBE aided in the diagnosis of small bowel CD in $12(75 \%) .{ }^{42}$ In another study of 14 patients with suspected small bowel CD, eight (57.1\%) had a diagnosis of $\mathrm{CD}$ after SBE. ${ }^{43}$

\section{Balloon-assisted enteroscopy versus other modalities}

A study of multiple medical centers in Korea indicated that DBE demonstrated definite CD in $80.0 \%$ of patients, whereas SBFT and computed tomography angiography revealed abnormal findings of small bowel CD in $73.1 \%$ and $64 \%$ of patients, respectively. ${ }^{36}$ MRE can diagnose small bowel CD accurately, and it offers the advantage of detecting mucosal abnormalities including transmural and extramural manifestations of CD. ${ }^{1}$ For ulcerative lesions, the sensitivity and specificity were of MRE were $82.4 \%$ and $87.6 \%$, respectively. In addition, for mucosal lesions, the sensitivity and specificity were of MRE were $67.5 \%$ and $94.8 \%$, respectively. ${ }^{44}$ However, MRE has some limitations. Although not commonly seen, the MRE procedure can be complicated by vomiting (11\%) and mild allergic rash (3\%) after intravenous contrast injection; ${ }^{3}$ moreover, histological results cannot be obtained at all by MRE in contrast to BAE. ${ }^{45}$

$\mathrm{CE}$ is an effective tool for diagnosing small bowel CD; however, capsule retention in stenotic small bowel CD and a lack of therapeutic applications limit its use. ${ }^{3}$ In small bowel $\mathrm{CD}, \mathrm{CE}$ use is also considerably hampered by the high prevalence of stenotic lesions. ${ }^{3}$ In addition, among the diagnostic endoscopy methods for $\mathrm{CD}, \mathrm{CE}$ is the most expensive. ${ }^{46} \mathrm{On}$ comparing BAE with $\mathrm{CE}$ in suspected small bowel $\mathrm{CD}$, a preliminary study of 44 patients who underwent a prior $\mathrm{CE}$ underwent DBE, after which CD was excluded in $9 \%$ of patients and a new diagnosis of CD was made in $14 \%{ }^{4}$

\section{Safety of balloon-assisted enteroscopy in small bowel CD}

$\mathrm{BAE}$ is a relatively safe procedure in suspected cases of CD, and there are only a few reports of complications. ${ }^{4}$ In one systemic review, which included 73 studies reporting 2,340 BAE procedures on 1,812 patients, in diagnostic DBE, the per-procedure perforation rate of CD was $0.12 \%$, which was similar to all indications $(0.22 \%)$. However, the per-procedure perforation rate in $\mathrm{CD}$ of therapeutic BAE was $1.74 \% .{ }^{47}$

\section{CONCLUSIONS}

Isolated before small bowel CD is a particularly difficult phenotype to diagnose, is highly resistant to treatment, and frequently results in complications. The early use of CE or BAE can aid in diagnosing symptomatic cases of suspected small bowel CD, possibly leading to early treatment and averting disastrous outcomes for these patients.

\section{Conflicts of Interest}

The authors have no financial conflicts of interest. 


\section{REFERENCES}

1. Hall B, Holleran G, McNamara D. Small bowel Crohn's disease: an emerging disease phenotype? Dig Dis 2015;33:42-51.

2. Chang CW, Wei SC, Chou JW, et al. Safety and efficacy of adalimumab for patients with moderate to severe Crohn's disease: the Taiwan society of inflammatory bowel disease (TSIBD) study. Intest Res 2014;12:287292

3. Wiarda BM, Mensink PB, Heine DG, et al. Small bowel Crohn's disease: MR enteroclysis and capsule endoscopy compared to balloon-assisted enteroscopy. Abdom Imaging 2012;37:397-403.

4. Bourreille A, Ignjatovic A, Aabakken L, et al. Role of small-bowel endoscopy in the management of patients with inflammatory bowel disease: an international OMED-ECCO consensus. Endoscopy 2009;41:618-637.

5. Satsangi J, Silverberg MS, Vermeire S, Colombel JF. The Montreal classification of inflammatory bowel disease: controversies, consensus, and implications. Gut 2006;55:749-753.

6. Efthymiou A, Viazis N, Mantzaris G, et al. Does clinical response correlate with mucosal healing in patients with Crohn's disease of the small bowel? A prospective, case-series study using wireless capsule endoscopy. Inflamm Bowel Dis 2008;14:1542-1547.

7. Iddan G, Meron G, Glukhovsky A, Swain P. Wireless capsule endoscopy. Nature 2000;405:417.

8. Jensen MD, Brodersen JB, Kjeldsen J. Capsule endoscopy for the diagnosis and follow up of Crohn's disease: a comprehensive review of current status. Ann Gastroenterol 2017;30:168-178.

9. Wei SC, Chang TA, Chao TH, et al. Management of Crohn's disease in Taiwan: consensus guideline of the Taiwan society of inflammatory bowel disease. Intest Res 2017;15:285-310.

10. Fireman Z, Mahajna E, Broide E, et al. Diagnosing small bowel Crohn's disease with wireless capsule endoscopy. Gut 2003;52:390-392.

11. Girelli CM, Porta P, Malacrida V, Barzaghi F, Rocca F. Clinical outcome of patients examined by capsule endoscopy for suspected small bowel Crohn's disease. Dig Liver Dis 2007;39:148-154.

12. Enns RA, Hookey L, Armstrong D, et al. Clinical practice guidelines for the use of video capsule endoscopy. Gastroenterology 2017;152:497-514.

13. American Society for Gastrointestinal Endoscopy Standards of Practice Committee, Shergill AK, Lightdale JR, et al. The role of endoscopy in inflammatory bowel disease. Gastrointest Endosc 2015;81:1101-1121.e1e13.

14. Monteiro S, Boal Carvalho P, Dias de Castro F, et al. Capsule endoscopy: diagnostic accuracy of Lewis score in patients with suspected Crohn's disease. Inflamm Bowel Dis 2015;21:2241-2246.

15. Gomollón F, Dignass A, Annese V, et al. 3rd European evidence-based consensus on the diagnosis and management of Crohn's disease 2016: part 1: diagnosis and medical management. J Crohns Colitis 2017;11:3-25.

16. Bar-Meir S. Review article: capsule endoscopy - are all small intestinal lesions Crohn's disease? Aliment Pharmacol Ther 2006;24 Suppl 3:19-21.

17. Annese V, Daperno M, Rutter MD, et al. European evidence based consensus for endoscopy in inflammatory bowel disease. J Crohns Colitis 2013;7:982-1018.

18. Kopylov U, Yung DE, Engel T, et al. Fecal calprotectin for the prediction of small-bowel Crohn's disease by capsule endoscopy: a systematic review and meta-analysis. Eur J Gastroenterol Hepatol 2016;28:1137-1144.

19. Mitselos IV, Christodoulou DK, Katsanos KH, et al. The role of small bowel capsule endoscopy and ileocolonoscopy in patients with nonspecific but suggestive symptoms of Crohn's disease. Eur J Gastroenterol Hepatol 2016;28:882-889.

20. Choi M, Lim S, Choi MG, Shim KN, Lee SH. Effectiveness of capsule endoscopy compared with other diagnostic modalities in patients with small bowel Crohn's disease: a meta-analysis. Gut Liver 2017;11:62-72.

21. Dionisio PM, Gurudu SR, Leighton JA, et al. Capsule endoscopy has a significantly higher diagnostic yield in patients with suspected and established small-bowel Crohn's disease: a meta-analysis. Am J Gastroenterol 2010;105:1240-1248; quiz 1249.

22. Tukey M, Pleskow D, Legnani P, Cheifetz AS, Moss AC. The utility of capsule endoscopy in patients with suspected Crohn's disease. Am J Gastroenterol 2009;104:2734-2739.

23. Hall B, Holleran G, Costigan D, McNamara D. Capsule endoscopy: high negative predictive value in the long term despite a low diagnostic yield in patients with suspected Crohn's disease. United European Gastroenterol J 2013;1:461-466.

24. Monteiro S, Dias de Castro F, Boal Carvalho P, et al. Essential role of small bowel capsule endoscopy in reclassification of colonic inflammatory bowel disease type unclassified. World J Gastrointest Endosc 2017;9:34-40.

25. Jensen MD, Nathan T, Rafaelsen SR, Kjeldsen J. Diagnostic accuracy of capsule endoscopy for small bowel Crohn's disease is superior to that of MR enterography or CT enterography. Clin Gastroenterol Hepatol 2011;9:124-129.

26. Harrington $C$, Rodgers $C$. The longest duration of retention of a video capsule. BMJ Case Rep 2014;2014

27. Cave D, Legnani P, de Franchis R, Lewis BS; ICCE. ICCE consensus for capsule retention. Endoscopy 2005;37:1065-1067.

28. Eliakim R. Video capsule endoscopy of the small bowel. Curr Opin Gastroenterol 2013;29:133-139.

29. Rezapour M, Amadi C, Gerson LB. Retention associated with video capsule endoscopy: systematic review and meta-analysis. Gastrointest Endosc 2017;85:1157-1168.e2.

30. Park SK, Ye BD, Kim KO, et al. Guidelines for video capsule endoscopy: emphasis on Crohn's disease. Clin Endosc 2015;48:128-135.

31. Van de Bruaene C, De Looze D, Hindryckx P. Small bowel capsule endoscopy: where are we after almost 15 years of use? World J Gastrointest Endosc 2015;7:13-36

32. Cooley DM, Walker AJ, Gopal DV. From capsule endoscopy to balloon-assisted deep enteroscopy: exploring small-bowel endoscopic imaging. Gastroenterol Hepatol (N Y) 2015;11:143-154.

33. Tharian B, Caddy G, Tham TC. Enteroscopy in small bowel Crohn's disease: a review. World J Gastrointest Endosc 2013;5:476-486.

34. Yamamoto H, Sekine Y, Sato Y, et al. Total enteroscopy with a nonsurgical steerable double-balloon method. Gastrointest Endosc 2001;53:216220 .

35. Rahman A, Ross A, Leighton JA, et al. Double-balloon enteroscopy in Crohn's disease: findings and impact on management in a multicenter retrospective study. Gastrointest Endosc 2015;82:102-107.

36. Jang HJ, Choi MH, Eun CS, et al. Clinical usefulness of double balloon enteroscopy in suspected Crohn's disease: the KASID multi-center trial. Hepatogastroenterology 2014;61:1292-1296.

37. Tun GS, Rattehalli D, Sanders DS, McAlindon ME, Drew K, Sidhu R. Clinical utility of double-balloon enteroscopy in suspected Crohn's disease: a single-centre experience. Eur J Gastroenterol Hepatol 2016;28:820-825.

38. Moschler O, May A, Müller MK, Ell C; German DBE Study Group. Complications in and performance of double-balloon enteroscopy (DBE): results from a large prospective DBE database in Germany. Endoscopy 2011;43:484-489.

39. Manno M, Barbera C, Bertani H, et al. Single balloon enteroscopy: technical aspects and clinical applications. World J Gastrointest Endosc 2012;4:28-32.

40. Kim J. Training in endoscopy: enteroscopy. Clin Endosc 2017;50:328333.

41. Riccioni ME, Urgesi R, Cianci R, Spada C, Nista EC, Costamagna G. Single-balloon push-and-pull enteroscopy system: does it work? A single-center, 3-year experience. Surg Endosc 2011;25:3050-3056.

42. Di Nardo G, Oliva S, Aloi M, et al. Usefulness of single-balloon enteroscopy in pediatric Crohn's disease. Gastrointest Endosc 2012;75:80-86.

43. de Ridder L, Mensink PB, Lequin MH, et al. Single-balloon enteroscopy, magnetic resonance enterography, and abdominal US useful for evalua- 
tion of small-bowel disease in children with (suspected) Crohn's disease. Gastrointest Endosc 2012;75:87-94.

44. Takenaka K, Ohtsuka K, Kitazume Y, et al. Comparison of magnetic resonance and balloon enteroscopic examination of the small intestine in patients with Crohn's disease. Gastroenterology 2014;147:334-342.e3.

45. Seiderer J, Herrmann K, Diepolder H, et al. Double-balloon enteroscopy versus magnetic resonance enteroclysis in diagnosing suspected small-bowel Crohn's disease: results of a pilot study. Scand J Gastroen- terol 2007;42:1376-1385.

46. Wei SC. Differences in the public medical insurance systems for inflammatory bowel disease treatment in Asian countries. Intest Res 2016;14:218-223.

47. Arulanandan A, Dulai PS, Singh S, Sandborn WJ, Kalmaz D. Systematic review: safety of balloon assisted enteroscopy in Crohn's disease. World J Gastroenterol 2016;22:8999-9011. 